\title{
A Genetic Approach to the Evaluation of Short Stature of Undetermined Aetiology
}

DOI:

10.1016/S2213-8587(18)30034-2

\section{Document Version}

Accepted author manuscript

Link to publication record in Manchester Research Explorer

\section{Citation for published version (APA):}

Murray, P., Clayton, P., \& Chernausek, S. (2018). A Genetic Approach to the Evaluation of Short Stature of Undetermined Aetiology. The Lancet Diabetes and Endocrinology. https://doi.org/10.1016/S2213-8587(18)30034-2

\section{Published in:}

The Lancet Diabetes and Endocrinology

\section{Citing this paper}

Please note that where the full-text provided on Manchester Research Explorer is the Author Accepted Manuscript or Proof version this may differ from the final Published version. If citing, it is advised that you check and use the publisher's definitive version.

\section{General rights}

Copyright and moral rights for the publications made accessible in the Research Explorer are retained by the authors and/or other copyright owners and it is a condition of accessing publications that users recognise and abide by the legal requirements associated with these rights.

\section{Takedown policy}

If you believe that this document breaches copyright please refer to the University of Manchester's Takedown Procedures [http://man.ac.uk/04Y6Bo] or contact uml.scholarlycommunications@manchester.ac.uk providing relevant details, so we can investigate your claim.

\section{OPEN ACCESS}


5 A Genetic Approach to the Evaluation of Short Stature of Undetermined Aetiology

6 Philip G Murray $\mathrm{PhD}^{1,2}$, Peter E Clayton $\mathrm{MD}^{1,2}$, Steven D Chernausek $\mathrm{MD}^{3}$

1. Department of Paediatric Endocrinology, Royal Manchester Children's Hospital, Central Manchester University Hospitals Foundation NHS Trust, Manchester Academic Health Science Centre, UK

2. Division of Developmental Biology and Medicine, School of Medical Sciences, Faculty of Biology, Medicine and Health, University of Manchester, UK.

3. Diabetes and Endocrinology, Department of Pediatrics, University of Oklahoma Health Sciences Center, Oklahoma, USA

Corresponding Author: Prof Steven D Chernausek, Professor of Paediatrics, Diabetes and Endocrinology, Department of Pediatrics, University of Oklahoma Health Sciences Center, 1200 N Phillips Ave, Suite 4500, OKC, OK 73104-4600

Tel 405-271-2767

Fax 405-271-3093

E-mail: Steven-Chernausek@ouhsc.edu

Word Count: 5258

Tables: 1

22

Figures: 3

Declaration of interests. PGM reports personal fees from Merck KGaA and Sandoz, and non-financial support from Pfizer. PEC reports other from Merck, Serono, Novo-Nordisk, and Pfizer. SDC reports personal fees from Novo-Nordisk and grant support from Ascendis and Versartis. No payment was made any pharmaceutical company to support the writing of this article. 
Short stature remains one of the commonest presentations to paediatric endocrinologists. After excluding major endocrine or systemic disease the majority of children with short stature currently receive a diagnosis based on a description of their growth pattern and height of their parents, e.g. familial short stature. Height has long been identified as a polygenic trait and genome wide association studies have identified many of the associated genetic loci. Here we review the application of genetic studies including copy number variant analysis, targeted gene panels and whole exome sequencing in children with idiopathic short stature. We estimate 25 to $40 \%$ of children with a diagnosis of idiopathic short stature could receive a molecular diagnosis using these technologies. Achieving a molecular diagnosis is not only important for the affected individuals and their families but may also inform treatment decisions surrounding the use of GH or IGF-I therapy.

\section{Search Strategy and Selection Criteria}

We searched the Cochrane Library, MEDLINE, and EMBASE for articles published between 2000 and November 2016. We used the search terms idiopathic short stature, short stature or small stature combined with body height. We also combined human growth hormone with idiopathic short stature/short stature/small stature. Clinical trials, guidelines, meta-analyses, multi-centre studies, randomized controlled trials and systematic reviews were given preference. We also searched the reference lists for articles identified by this search strategies and selected those we judged relevant.

\section{Introduction}

Concerns about short stature are among the most common reasons parents seek consultation with a growth specialist, accounting for about half of new visits to a paediatric endocrine practice. Despite standard clinical and laboratory evaluation, a pathologic diagnosis is not reached in 50-90 \% of cases. Most of these children are labelled as either constitutional delay of growth and puberty, familial short stature, or idiopathic short stature (ISS) $)^{1-3}$, which are simply descriptive terms of overlapping populations. Although there is general consensus with regards to classification and effectiveness of therapies (e.g. a short course sex steroid for delayed puberty and recombinant human growth hormone [r-hGH] for ISS), there remains uncertainty and controversy about the diagnostic approach and treatment (r-hGH is not licenced for ISS in all countries), all occurring in the background of persistent ethical concerns about "medicalizing" variants of normal and the potential for harm by growth stimulating agents ${ }^{4,5}$. Consensus guidelines address some of these issues, the most recent exclusively for idiopathic short stature were published in $2008^{6}$ and for the children born small for gestational age (SGA) in $2007^{7}$ and $2011^{8}$ with guidelines on GH treatment for short-statured children published in $2016^{9}$. Since then there have been significant changes in our ability to use molecular genetic tests to diagnose and classify these children.

The most widely accepted definition for idiopathic short stature (ISS) is a height more than 2 standard deviations below the mean for age and sex and where no aetiology is revealed following a detailed history, physical examination, and limited laboratory testing ${ }^{6,10}$. Typically stature is below -2 SDs by age 2-3 years following a normal birth weight, and then either remains at this relative constant deficit or gradually falls to even lower percentiles during childhood with an acceleration of growth during puberty (FIGURE 1). Thus, ISS would include cases of familial short stature (a short child in the range expected given parental stature) and some cases of constitutional delay of growth and puberty, i.e. a child shorter than expected for parental size but with a delay in pubertal maturation.

One of the challenges for this review is how to deal with the arbitrary and perhaps misleading separation of ISS from other conditions. The postnatal growth pattern of the short child born SGA is similar to that of a child with ISS and the mechanisms responsible for the poor growth for most remain unknown ${ }^{6,11}$. Furthermore many young patients with constitutional delay of growth and puberty are indistinguishable from those with ISS prior to puberty. Since all these are short at some time in life and the aetiology of the short stature unknown, they all could be considered to have "idiopathic short stature, i.e. ISS". Thus, for this review we have chosen to broaden discussion and, in the absence of a specific diagnosis and will use the term short stature when referring to classical ISS and the related populations, including those born SGA. 
Several reports have detailed spontaneous growth and adult height in children with ISS and generally reach the same conclusions ${ }^{12-14}$. Two thirds to three quarters achieve adult stature within the normal range although most are below average. As a group, mean adult height approximates -1.5 SDS. The increase in the height SDS as adults compared to that observed during childhood is due to a delay in pubertal onset of approximately one year, which extends the growing period. These observations are backed up by randomized controlled trials of r-hGH in ISS or short children born SGA, which show that untreated controls increase their height SDS score by the time they reach adult height ${ }^{15-18}$.

Most children with ISS reach adult heights in the normal range, yet it has proved very difficult to separate out who are at high risk for permanent short stature. Several factors are associated with poorer height outcome in the absence of treatment (e.g. shorter parents, lower predicted adult height based on stature/bone age $)^{14}$. However, the influence of these factors is not robust enough to predict eventual height in an individual patient with sufficient accuracy.

Randomized controlled trials of r-hGH in ISS and short children born SGA demonstrate clearly that $r$ hGH accelerates growth and increases adult height when administered for several years. Increases in adult height SDS approximate $1 \mathrm{SD}$, but height gains vary among individuals and by study ${ }^{15-18}$. Treatment of short stature, with the exception of where the height deficit is sufficient to impede function or require adaptation, is undertaken with the expectation that a greater height will mitigate the adverse psychosocial effects of short stature and be of lasting benefit. Although some studies have attempted to examine such effects of r-hGH treatment, results have been variable and perhaps subjected to flaws in study design ${ }^{19}$. In the end it remains difficult to know whether for some reassurance and counselling may be a better treatment than daily injections. Presently the treating physician must weigh the pros and cons of intervention for each individual.

Although r-hGH is approved in several countries for treatment for short children with ISS without GH deficiency, the use of r-hGH in these conditions remains controversial because of the variable response to growth hormone therapy ${ }^{20}$, uncertainty as to the exact benefit of the intervention, and concerns about long-term safety. Many of these issues stem from the fact that patients classified as ISS or related conditions are a mixture of pathologies that affect growth. As we now appreciate the wide variety of molecular genetic variants that impact stature, it is expected that these may be predictive of adult height, responsiveness to treatment, and risk of adverse effects. The purpose of this review is to provide an update on potential approaches to the evaluation of the child with short stature of undetermined aetiology, in particular focussing on genetic investigation and implications to management.

\section{Current Diagnostic Approach}

When no clear diagnosis for the short child is forthcoming from the history and examination, then a range of investigations can be undertaken, including testing to exclude occult system disease, surveying for subtle skeletal abnormalities, screening for hormone deficiencies and major genetic anomalies. Detailed recommendations on standard evaluation of short stature are provided in several publications ${ }^{6,21,22}$.

Although a patient with ISS, by definition, is not GH deficient, there has been a great deal of investigation into the potential role of perturbations in the GH/IGF axis as a basis for their reduced stature. These studies were largely driven by the increased availability of $\mathrm{r}-\mathrm{hGH}$ and data that defined the roles of GH and IGF as major regulators of skeletal growth ${ }^{23,24}$. Because both GH secretion and responsiveness exist along a continuum (with severe GH deficiency and GH insensitivity residing at the ends of the spectrum) ${ }^{25}$ subtle alterations in either GH secretion or action may underlie cases of ISS; this is supported by studies showing that circulating levels of IGF-1 are typically lower on average in ISS children ${ }^{26,27}$ with up to $50 \%$ of ISS children having subnormal levels ${ }^{26,28}$. Therefore a short child with no clear diagnosis typically undergoes testing of the GH-IGF axis. The majority will have normal peak GH levels during stimulation testing with a normal or low IGF1 concentration. Treatment with r-hGH can be initiated in those countries that have licensed r-hGH for ISS or the short child born SGA; r-hIGF1 may be indicated for those with GH insensitivity/primary IGF deficiency ${ }^{9}$.

The skeletal dysplasias are a heterogeneous group of over 450 genetic disorders of cartilage and bone ${ }^{29}$ and need to be excluded in patients classified as ISS. While these disorders often produce clinically obvious disproportionate short stature, there is wide phenotypic variability as evidenced by studies identifying short stature due to $S H O X^{30}$ or $F G F R 3^{31}$ mutations/deletions in patients with ISS without obvious dysplasia. Flechtner $e a^{32}{ }^{32}$ systematically evaluated the prevalence of skeletal dysplasias in a cohort of children referred to 
an endocrine/growth disease centre. A skeletal dysplasia was identified radiographically in 51/234 (21.8\%) ISS patients with an increase in prevalence where one parent was also affected $(21 / 63,33.3 \%, \mathrm{p}=0.009)$. This high diagnostic yield may reflect ascertainment bias as the study was undertaken in a reference centre for skeletal dysplasias. None-the-less, the results underscore the need for considering skeletal dysplasia in patients with apparent ISS.

During the evaluation of a child for short stature disorders of imprinting must also be considered. The most widely recognised is Silver-Russell syndrome which is caused by maternal uniparental disomy of chromosome 7 (5-10\% of cases) or hypomethylation of the paternally inherited allele at chromosome 11p15 (30$60 \%$ cases) which results in suppression of $I G F 2$ transcription $^{33}$. Recently a small number of families have been identified where Silver-Russell Syndrome has been caused by paternally inherited IGF2 mutations ${ }^{34}$. Short stature is also seen in Prader-Willi syndrome which results from paternal deletions at 15q11.2-q13, uniparental disomy of chromosome 15 or an imprinting defect ${ }^{35}$. Pseudohypoparathyroidism is also associated with short stature and caused by a variety of genetic mechanisms including methylation abnormalities, maternal deletions or uniparental disomy of chromosome $20^{36}$. Silver-Russell, Prader-Willi and pseudohypoparathyroidism are well described and familiar to most clinicians, Temple syndrome, caused by maternal uniparental disomy of chromosome 14, paternal deletions or imprinting defects at chromosome 14q32 is less well recognised ${ }^{37}$. Clinical features of Temple syndrome include low birth weight, short stature, hypotonia, motor delay, early puberty, small hands/feet and obesity.

\section{Rationale for more detailed genetic investigation}

The role of specific genes as determinants of both normal and pathologic human growth has been actively investigated during the last decade, catalysed by tremendous advances in the ability to identify gene variants and their functional consequences. Early twin and adoption studies indicate that adult height is 80$90 \%$ heritable ${ }^{38-40}$. Thus far, genome wide association studies have explained $27.4 \%$ of the adult variation in human height with 780 variants identified from a population of 711,428 healthy individuals ${ }^{41,42}$. This analysis includes effects of both common and rare variants on height. Of note the effect size of rare variants was more than 10 fold higher than that of the common variants. The current estimate that $27.4 \%$ of height can be explained by known variants may be an underestimate as analysis using imputed variants explains up to $56 \%$ of variation in height ${ }^{43}$. Therefore it is near certain that the reduced stature of many ISS patients has a genetic basis. For some, this will be due to a variation in expression or function of a single gene product (monogenic) whereas for others the condition is the result of accumulation of multiple height impairing variants (oligogenic or polygenic). As well as height, age at menarche (and hence likely age at pubertal onset) also has a genetic basis having been linked to 397 genetic variants ${ }^{44}$. Such genetic variants are likely to affect the tempo of growth and puberty and may contribute to the phenotype seen in CDGP.

\section{Exemplars of targeted investigation}

\section{The single gene approach}

These studies examine the frequency of mutations in candidate genes in ISS and related conditions. Perhaps the best example are studies of SHOX (short stature homeobox), the first genetic cause of ISS reported in $1997^{45}$ and also a cause of Leri-Weill dyschondrosteosis ${ }^{46}$. Mapping studies followed by sequencing identified a single SHOX mutation in 1/91 (1.1\%) ISS patients, demonstrating that mutation of a single gene may cause syndromic forms of short stature in some children, while in others affecting stature with minimal additional clinical features. Subsequent studies now place the prevalence of SHOX abnormalities in ISS at between 3-15\% $\%^{46-49}$. In addition, genetic abnormalities within the pseudoautosomal region 1 (PAR1) of the sex chromosomes (where SHOX resides) have all been associated with short stature disorders and affect SHOX expression $^{50-53}$. Interestingly, patients carrying a SHOX enhancer deletion are less disproportionate and respond better to GH therapy than patients with SHOX haploinsufficiency ${ }^{54}$.

Mutation of NPR2, the gene encoding the receptor for C-type naturetic peptide, represents another circumstance where the phenotype varies from clinically obvious skeletal dysplasia to ISS. Initially associated with the autosomal recessive skeletal dysplasia, acromesomelic dysplasia, the finding of reduced height in carriers in affected families ${ }^{55}$ led to the identification of NPR2 mutations in $6 \%$ of children with ISS ${ }^{56}$ with $1 / 3$ 
having disproportionate short stature. Another report identified 6 pathological NPR2 mutations in a cohort of 95 ISS and 173 suspected Leri-Weill dyschondrosteosis patients (all with no known defect in SHOX/PAR1) ${ }^{57}$.

Given the key role of the GH-IGF1 axis in growth and the common finding of low IGF1 in ISS patients $^{26,27}$, several studies have SOUGHT mutations in the genes encoding components of this axis in undiagnosed short patients. An increased frequency of mutations in such short children compared to controls has been found for the GH secretagogue receptor $G H S R^{58}, I G F 1^{59,60}$, IGF acid labile subunit $I G F A L S^{61}$ and $I G F I R$

${ }^{30}$. Recently loss of function mutations in pregnancy-associated plasma protein A2 (PAPPA2) have been identified in two families with previously unexplained short stature ${ }^{62}$. The patients presented with raised concentrations of GH, IGF-I, IGFBP-3, ALS and IGFBP5. PAPPA2 encodes a metalloproteinase responsible for cleavage of IGFBP-3 and IGFBP-5, an essential step in the generation of free IGF-I. The prevalence of PAPPA2 mutations in general population of short children has not yet been examined.

\section{The multi-gene approach}

The studies described above all focussed on a single or very limited number of genes, typically identifying the cause in $5 \%$ or less of the population. The low yield is not surprising given the $\sim 700$ genes known to affect growth, but the studies serve as proof of principle that cryptic gene mutations are plausible causes of ISS. Targeted Next Generation Sequencing is more broad-based approach that has been used in cohorts of ISS subjects. Multi-gene studies typically analyse a host of genes that are either known to cause short stature, are linked to adult height by genome wide association studies or are known to be involved in growth through animal or in vitro studies. Two main approaches have been taken-a) assessing differences in SNP frequency between control and ISS populations in order to locate allelic variants influencing growth or, $b$ ) examining candidate genes for pathological mutations.

De Graaff et al investigated 225 SNPs in 10 genes linked to growth and glucose metabolism (GH1, GHR, IGF1, IGF1R, STAT5A, STAT5B, MAPK1, MAPK3, PPAR $\gamma$ and INS) in 1,437 ISS and SGA patients. Only one SNP (rs4966035, IGFIR) was significant and was associated with being SGA ${ }^{63}$. In another study of 155 ISS patients and 318 normal controls, two SNPs within HMG2A, a gene where variants have previously been associated with adult height, were found to be associated with ISS ${ }^{64}$. The EPIGROW study examined 232 candidate genes via next generation sequencing in 263 ISS and SGA patients. Two SNPs in ZBTB38 5'UTR and promotor region as well as two insertions/deletions (one in $I G F I$ and one in $N F K B 1$ ) were significantly different between cases and controls ${ }^{28}$. Such studies indicate that gene variants contribute to short stature, but do not often provide a precise diagnosis. $H M G 2 A$ (also called $H M G B 3$ ) expression has been associated with poor prognosis for several tumour types ${ }^{65-67}$ while ZBTB38 regulates DNA replication ${ }^{68}$ and has been found to be mutated in a rare mucinous neoplasm and NFKB1 insertion/deletions are also linked to cancer risk ${ }^{69}$.

Wang et $\mathrm{al}^{70}$ screened 1077 candidate genes (366 associated with known short stature disorders) in a heterogeneous cohort of 192 children with short stature (16\% GHD, 15\% developmental delay and 7\% with a syndromic diagnosis but no identified mutation). A definitive diagnosis, where a known pathological variant was identified and the patient's phenotype matched that of the known variant, was made in only 4 patients $(2 \%)$ -3 cases of Noonan syndrome and 1 case of brachyolmia type 3 . There were a further 64 variants identified from the 192 children where the variant was a previously identified pathogenic mutation but the patient phenotype did not match that previously reported. Some of these variants are likely to represent prior false attributions but some may also represent phenotypic variability and thus the diagnostic yield could well be higher than the reported $2 \%$.

\section{Genome-wide approach}

These studies use less biased approaches to survey the genome for the putative cause of short stature. The methods employed can detect known pathologic variants in individuals who may manifest short stature as the only sign of a syndromic condition but also can lead to the discovery of novel genes and pathways involved in growth control. Most commonly these utilize either competitive genome hybridization (cGH) or SNP arrays to detect copy number variants (CNVs) or whole exome sequencing (WES) to examine coding regions of the entire genome. Usually CNV analysis is undertaken prior to WES as, unlike WES, CNV analysis is well established as part of routine clinical care and more widely available. 
The human genome contains multiple regions of genomic DNA copy number gain or loss (i.e. CNVs) which can range from kilobase to megabase $\operatorname{size}^{71}$. cGH-arrays most often provide a genetic descriptor rather than a specific diagnosis. An array however can be an important step in the evaluation of ISS children, as it may suggest a more precise genetic diagnosis (e.g. deletion of a part of a chromosome that is the location of a key gene, e.g. the IGF1 receptor $[I G F 1 R])$. Copy number variant studies have revealed a range of abnormalities in short stature, as summarised below.

Dauber et al reported the relationship between stature and CNV frequency using in a cohort of 4411 individuals with childhood/early adulthood height data (mean height SDS -0.19$)^{72}$. Subjects with a height SDS of <-2 SD had a 1.26 fold increase in average CNV length ${ }^{72}$; thus there is an increased CNV burden in individuals with short stature. This increase in CNV burden was significant for deletions (but not duplications) with a population frequency of $<5 \%$, with rare deletions being increased 2.3 fold in the short individuals. This study, however, did not seek to identify individual pathogenic CNVs in the individuals with short stature but subsequent studies ${ }^{73-76}$ have attempted to address that question.

In a cohort of 200 individuals with short stature (131 isolated short stature and 69 syndromic short stature), Zahnleiter et al identified 20 patients (10\%) with presumptive pathogenic CNVs, 10 were duplications and 10 deletions ${ }^{75}$. Eight were associated with known microdeletion/duplication syndromes and a further two contained known stature-determinant genes. For the remaining CNVs there was strong evidence that they were pathogenic as all contained genes associated with adult height, growth pathways or a mouse growth retardation phenotype and in addition were either de novo or, where inherited, segregated with short stature in the family. Individuals with such CNVs had an increased rate of intellectual disability (9/20 CNV patients) and lower height SDS (-3.34 SD vs -2.75 SD) when compared to those individuals without a CNV. The probability of detecting a CNV was increased in subjects born SGA (15\% SGA subjects vs $8 \%$ AGA subjects). In a similar study van Duyvenvoorde et al genotyped 149 families containing individuals classified as ISS or SGA and identified CNVs containing known short stature genes in 6 families (4\%: 4 SHOX deletions/duplications and 2 IGF1R deletions $)^{76}$. In an additional $13(8.7 \%)$ families a potentially pathogenic CNV was identified which was either de novo or segregated with short stature in the family. Additional studies report similar diagnostic yields $^{73}$. Future work to include functional studies is likely to refine the diagnostic yield from CNV studies by improving the classification of such CNVs as pathogenic and non-pathogenic. The use of SNP arrays is likely to improve diagnostic yield compared to array CGH as SNP arrays can also identify uniparental disomy.

Recently investigators have turned to WES for short stature disorders in order to uncover pathogenic alleles, both known and novel. Nilsson et al identified autosomal dominant aggrecan (ACAN) mutations in 3 families with ISS and an advanced bone age ${ }^{77}$. The encoded protein, aggrecan, is an extracellular matrix proteoglycan, and $A C A N$ mutations had previously been reported in patients with spondyloepimetaphyseal dysplasia $^{78}$. Guo et al examined 14 children with short stature (height SDS <-3) of unidentified cause using WES and reached a genetic diagnosis in 5 children (2 with 3-M syndrome and one each with Kenny-Caffey Syndrome, Floating-Harbour Syndrome and the progerioid variant of Ehlers Danlos Syndrome) giving a diagnostic yield of $36 \%{ }^{79}$. For two of these patients (Kenny-Caffey and Ehlers Danlos Syndrome), the phenotype was mild. The 14 patients recruited to the study by Guo et al were selected from a larger cohort of 192 patients and the diagnostic yield is likely to have been increased by the selection process and by the use of an inclusion criteria of height SDS <-3.

Thus far reports frequently assessed patients with dysmorphic features and/or radiological features of skeletal dysplasia and thus atypical for patients with ISS. However, it is likely that further application of exome sequencing in the SGA and ISS populations will identify additional patients with pathogenic mutations affecting genes associated with a syndromic diagnoses but who lack characteristic features.

\section{Proposed Approach to the ISS child (figure 2)}

We now suggest that for those ISS children with marked short stature (Height SDS <-3) undertaking more detailed genetic investigation should be considered to reach a precise diagnosis. There are many benefits to this. These include the removal of the need to undertake further evaluations - many of these children currently undergo batteries of expensive tests. Prognosis and counselling are much better informed when a diagnosis is reached, with screening for associated health issues. Genetic testing can also be undertaken in the wider family. There are, however, some drawbacks. A precise diagnosis removes the ISS label and in some 
countries the licenced indication for $\mathrm{r}-\mathrm{hGH}$. Conversely, identification of a SHOX mutation could provide a licensed indication for $\mathrm{r}$-hGH when treatment of ISS is not approvable. A novel variant may be identified, which is predicted to be pathogenic, but cannot be confirmed as causative without other reports and/or complex functional analysis. In our opinion, benefits outweigh drawbacks and our suggested approach illustrated in Figure 2. The algorithm describes scenarios that either suggest particular lines of investigation depending on the presence or absence of clinical features.

Patients with subtle features suggestive of a particular condition (e.g. Scenario 2, SHOX, NPR2 or $A C A N$ deficiency) should be prioritized for individual gene sequencing. A higher prevalence of SHOX/PAR1 abnormalities is seen among ISS patients where there are some features of Leri-Weill dyschondrosteosis such as disproportionate short stature ${ }^{48,80}$ or a family member with Madelung deformity ${ }^{47}$. There will remain, however, a considerable number of patients with pathogenic SHOX variants who have body proportions within the normal range, this is especially common in those patients with deletions of SHOX enhancers and without increased routine genetic analysis these patients will not receive appropriate therapy. In addition, the prevalence of NPR2 mutations in an ISS population depends on the extent of anthropometric and radiographic assessments ${ }^{57}$. Therefore careful measurements of body proportions (e.g. sitting height, arm span, upper-lower segment ratio, and head circumference) and a skeletal survey would identify those ISS children on whom a targeted search for mutations in these genes would be worthwhile. Techniques and reference ranges for these measures in North American can be found at https://www.cdc.gov/nchs/nhanes/index.htm. Norms for other populations are also available $^{81,82}$.

In the absence of phenotypic or biochemical pointers, one route to increase molecular diagnosis rates in children would be the use of either targeted panels of genes linked to growth disorders or high resolution chromosomal microarray analysis (e.g. scenarios 3 and 4). CGH or SNP arrays detect pathogenic CNVs in 17$19 \%$ of patients with developmental delay or intellectual disability, a finding which prompted the American College of Medical Genetics and Genomics to recommend chromosomal microarray analysis as a first tier clinical diagnostic test for these individuals ${ }^{83}$. For ISS children, a diagnostic yield of 5-10\% for identifying CNVs known to be associated with short stature is expected based on published studies. Another 5-10\% of patients have CNVs which are highly likely to be pathogenic, giving a potential total diagnostic yield of 10$20 \%^{73-75}$.

With the falling cost of next generation sequencing (NGS, exome and whole genome), this approach is likely to play an increasingly useful role in the evaluation of children with unexplained short stature. The threshold such testing is arbitrary and dependent on the presence of clinical features that raise the chance of detecting of an important genetic anomaly. The review by Dauber et $\mathrm{al}^{84}$ outlines an approach for diagnosis of suspected monogenic growth disorders. Diagnostic yield will be highest in patients with severe short stature, additional affected family members (while both affected and unaffected family members will increase yield from exome sequencing the presence of two or more affected family members raises the probability that the cause of short stature is likely to be monogenic in origin), and dysmorphic features (i.e. children in whom there are dysmorphic features but in whom a clinical syndromic diagnosis has not been made). In short children without affected family members, normal biochemistry and no dysmorphic features the diagnostic yield is likely to be low but over time will improve as further genetic causes of short stature are identified. Interpretation of whole exome/genome data requires intensive bioinformatics support and clinical experience to correctly interpret the results. Further studies evaluating larger cohorts of unselected ISS and SGA children are required to evaluate the diagnostic yield and current cost-effectiveness of using NGS sequencing in these cohorts. Using copy number variant analysis, targeted single gene sequencing and next generation sequencing, we estimate that up to $25-40 \%$ of the children currently diagnosed with ISS and height SDS <-3 could receive a more specific diagnosis. As our knowledge of the genetic causes of ISS increases, the diagnostic yield from whole exome/genome studies is likely to increase, which in combination with the rapidly falling costs of sequencing is likely to lead to the routine clinical use of this technology in short stature patients.

\section{Therapeutic implications}

It remains a challenge to select the ISS patients and those with related conditions most likely to benefit from the use of growth-promoting agents. Treatment is generally more effective when initiated at a young age, but that is a time when it is very difficult to predict adult height for those left to follow their natural course. 
Achieving a specific diagnosis therefore has the potential to aid in treatment decisions. For example, the finding of an IGFALS defect in a child with moderate growth impairment could lead to a decision not to treat at all, as many patients naturally achieve a normal adult height and rhGH treatment may not be efficacious ${ }^{85-87}$.

Additionally in the SGA population, NGS may reveal a diagnosis such as Fanconi or Bloom syndrome, in which growth-promoting treatments would be contraindicated because of risk for malignancy. The finding of an $I G F 1 R$ mutation would support the use of $\mathrm{r}-\mathrm{hGH}$ to attempt to overcome this receptor block ${ }^{88,89}$. Reported evidence of the effect of $\mathrm{r}-\mathrm{hGH}$ in those with $A C A N$ mutations could support a trial of treatment ${ }^{90}$.

There is also the potential for genetic information to guide dosing decisions or to determine whether rhGH or r-hIGF1 is the preferred treatment. Up to $50 \%$ of ISS children have a low IGF-I level in association with normal or even high GH secretion ${ }^{28}$. This may indicate a degree of GH insensitivity, requiring either higher $\mathrm{r}$-hGH doses or treatment with r-hIGF1. A common isoform of the GH receptor (exon 3 deletion) has reduced GH signalling in vitro and thus appeared to be a good candidate for predicting GH sensitivity in vivo ${ }^{91}$. Although most studies show that harbouring the variant has limited impact on the growth in response to r$\mathrm{hGH}^{92}$, the potential for other genetic variants in ISS to affect responsiveness remains high given the varied outcomes in ultimate stature for $\mathrm{r}$-hGH-treated ISS patients and the convincing evidence that they display a range of sensitivities to GH and IGF1 ${ }^{93}$.

Some children will meet criteria for initiating rh-IGF1 treatment. This 'biochemical' diagnosis of primary IGF deficiency is classically associated with mutations in the GH-IGF pathway including the GH receptor, STAT5B, IGF1 and IGFALS, but can also be seen in the rasopathies, defects associated with the NF$\mathrm{kB}$ pathway ${ }^{94}$ and various syndromes e.g. $3-\mathrm{M}^{95}$. Therefore the identification of an abnormality in the GHR, $S T A T 5 B$ or IGF1 genes in an ISS child would mean that r-hIGF1 treatment could be considered, in particular if r-hGH has been tried and failed. In other circumstances where IGF1 bioavailability is adversely affected, as found the newly described PAPPA2 deficiency ${ }^{62}$, r-hIGF1 may have a therapeutic role ${ }^{96}$.

\section{Conclusions}

Decades ago evaluation of growth disorders was largely restricted to auxological description and treatment employed limited amounts of pituitary-derived growth hormone in select individuals. The advent of radioimmunoassay led to the ability to measure hormones in the bloodstream followed by the elucidation of growth hormone signalling mechanisms involving the IGFs, receptors, etc. Subsequently the field advanced to where a patient's condition was defined by hormonal profiles and the status of their growth hormone/IGF axis. The focus on growth hormone and its partners was logical given the pronounced role in growth regulation $(\mathrm{GH}$ and IGFs being responsible for about $70 \%$ of growth of mammals ${ }^{97}$ ) and the availability of r-hGH and later rhIGF1 as therapeutic agents.

Our perspective on the determinants of stature has broadened tremendously over the last decade, driven by ever more sophisticated and extensive studies of the genome (Figure 3). Many of the genes encoding proteins required for normal growth in height are expressed in the skeletal growth plate, from which all linear growth is derived $^{98}$. Thus, we now enter a time when genetic data will be used to better define and diagnose growth disorders, expanding our knowledge much as hormone measures did in the past. Such testing should augment the evaluation, not replace auxological data and hormone measures. Assessment of the GH/IGF axis remains key as many presently available interventions involve this pathway. With technological advancements allowing the assay of genetic information proceeding extremely rapidly, genetic tests certainly will soon become common place in the routine evaluation of growth disorders and useful to reach specific diagnoses as well as guide treatment.

Given the power of currently available genetic analyses and high heritability of height, it is perhaps somewhat disappointing that diagnostic yields are not higher, especially in non-syndromic ISS. However, the complexities of genetic expression/interaction far exceed what most of us imagined. The current approach is predominantly Mendelian, using tests that seek to explain the growth deficit by a defect in a single gene. The limitation of this is evidenced by the fact that polymorphisms at 700 loci explain only half of heritability of stature in humans. While ISS will be the result of a single gene mutation having a profound impact on growth in some patients, for others their growth attenuation will be the result of multiple gene variants, each variant having a lesser effect but collectively leading to significant growth impairment. In addition, changes in the expression of growth-determining genes resulting from epigenetic mechanisms such as cytosine methylation, 
histone acetylation, or microRNA abundance remain to be explored. Though our inability to fully examine

391 these mechanisms stands as a limitation at present, it also offers an opportunity to expand our understanding of growth control and eventually explain the basis of short stature in the majority of those affected. 
395 1. Goldyn AK, Nabhan ZM, Eugster EA. A comparison of referral patterns to the pediatric endocrine clinic before and after FDA approval of growth hormone for idiopathic short stature. Journal of pediatric endocrinology \& metabolism : JPEM 2011; 24(1-2): 89-91.

2. Lindsay R, Feldkamp M, Harris D, Robertson J, Rallison M. Utah Growth Study: growth standards and the prevalence of growth hormone deficiency. The Journal of pediatrics 1994; 125(1): 29-35.

3. Song KC, Jin SL, Kwon AR, et al. Etiologies and characteristics of children with chief complaint of short stature. Annals of pediatric endocrinology \& metabolism 2015; 20(1): 34-9.

4. Allen DB. Clinical review: Lessons learned from the hGH era. The Journal of clinical endocrinology and metabolism 2011; 96(10): 3042-7.

5. Pedicelli S, Peschiaroli E, Violi E, Cianfarani S. Controversies in the definition and treatment of idiopathic short stature (ISS). Journal of clinical research in pediatric endocrinology 2009; 1(3): 105-15. 6. Cohen P, Rogol AD, Deal CL, et al. Consensus statement on the diagnosis and treatment of children with idiopathic short stature: a summary of the Growth Hormone Research Society, the Lawson Wilkins Pediatric Endocrine Society, and the European Society for Paediatric Endocrinology Workshop. The Journal of clinical endocrinology and metabolism 2008; 93(11): 4210-7.

7. Clayton PE, Cianfarani S, Czernichow P, Johannsson G, Rapaport R, Rogol A. Management of the child born small for gestational age through to adulthood: a consensus statement of the International Societies of Pediatric Endocrinology and the Growth Hormone Research Society. J Clin Endocrinol Metab 2007; 92(3): 804-10.

8. Boguszewski MC, Mericq V, Bergada I, et al. Latin American consensus: children born small for gestational age. BMC Pediatr 2011; 11: 66.

9. Grimberg A, DiVall SA, Polychronakos C, et al. Guidelines for Growth Hormone and Insulin-Like Growth Factor-I Treatment in Children and Adolescents: Growth Hormone Deficiency, Idiopathic Short Stature, and Primary Insulin-Like Growth Factor-I Deficiency. Hormone research in paediatrics 2016; 86(6): 361-97. 10. Lee PA, Chernausek SD, Hokken-Koelega AC, Czernichow P, International Small for Gestational Age Advisory B. International Small for Gestational Age Advisory Board consensus development conference statement: management of short children born small for gestational age, April 24-October 1, 2001. Pediatrics 2003; $111(6$ Pt 1): 1253-61.

11. Wit JM. Definition and subcategorization of idiopathic short stature: between consensus and controversy. Hormone research in paediatrics 2011; 76 Suppl 3: 3-6.

12. Rekers-Mombarg LT, Wit JM, Massa GG, et al. Spontaneous growth in idiopathic short stature. European Study Group. Archives of disease in childhood 1996; 75(3): 175-80.

13. Price DA. Spontaneous adult height in patients with idiopathic short stature. Hormone research 1996; 45 Suppl 2: 59-63.

14. Ranke MB, Grauer ML, Kistner K, Blum WF, Wollmann HA. Spontaneous adult height in idiopathic short stature. Hormone research 1995; 44(4): 152-7.

15. Carel JC, Chatelain P, Rochiccioli P, Chaussain JL. Improvement in adult height after growth hormone treatment in adolescents with short stature born small for gestational age: results of a randomized controlled study. J Clin Endocrinol Metab 2003; 88(4): 1587-93.

16. Van Pareren Y, Mulder P, Houdijk M, Jansen M, Reeser M, Hokken-Koelega A. Adult height after long-term, continuous growth hormone $(\mathrm{GH})$ treatment in short children born small for gestational age: results of a randomized, double-blind, dose-response GH trial. J Clin Endocrinol Metab 2003; 88(8): 3584-90.

17. Leschek EW, Rose SR, Yanovski JA, et al. Effect of growth hormone treatment on adult height in peripubertal children with idiopathic short stature: a randomized, double-blind, placebo-controlled trial. The Journal of clinical endocrinology and metabolism 2004; 89(7): 3140-8.

18. Albertsson-Wikland K, Aronson AS, Gustafsson J, et al. Dose-dependent effect of growth hormone on final height in children with short stature without growth hormone deficiency. J Clin Endocrinol Metab 2008; 93(11): 4342-50.

19. Gardner M, Boshart ML, Yeguez CE, Desai KM, Sandberg DE. Coming Up Short: Risks of Bias in Assessing Psychological Outcomes in Growth Hormone Therapy for Short Stature. The Journal of clinical endocrinology and metabolism 2016; 101(1): 23-30.

20. Wit JM, Reiter EO, Ross JL, et al. Idiopathic short stature: management and growth hormone treatment. Growth Horm IGF Res 2008; 18(2): 111-35.

21. Ranke MB. Treatment of children and adolescents with idiopathic short stature. Nature reviews Endocrinology 2013; 9(6): 325-34.

22. Oostdijk W, Grote FK, de Muinck Keizer-Schrama SM, Wit JM. Diagnostic approach in children with short stature. Hormone research 2009; 72(4): 206-17. 

encoding insulin-like growth factor I (Igf-1) and type 1 IGF receptor (Igf1r). Cell 1993; 75(1): 59-72.

24. Woods KA, Camacho-Hubner C, Savage MO, Clark AJ. Intrauterine growth retardation and postnatal growth failure associated with deletion of the insulin-like growth factor I gene. The New England journal of medicine 1996; 335(18): 1363-7.

25. Savage MO, Burren CP, Rosenfeld RG. The continuum of growth hormone-IGF-I axis defects causing short stature: diagnostic and therapeutic challenges. Clinical endocrinology 2010; 72(6): 721-8.

26. Blair JC, Camacho-Hubner C, Miraki Moud F, et al. Standard and low-dose IGF-I generation tests and spontaneous growth hormone secretion in children with idiopathic short stature. Clin Endocrinol (Oxf) 2004; 60(2): 163-8; discussion 1-2.

27. Ross JL, Lee PA, Gut R, Germak J. Attaining genetic height potential: Analysis of height outcomes from the ANSWER Program in children treated with growth hormone over 5 years. Growth Horm IGF Res 2015; 25(6): 286-93.

28. Clayton P, Bonnemaire M, Dutailly P, et al. Characterizing short stature by insulin-like growth factor axis status and genetic associations: results from the prospective, cross-sectional, epidemiogenetic EPIGROW study. The Journal of clinical endocrinology and metabolism 2013; 98(6): E1122-30.

29. Warman ML, Cormier-Daire V, Hall C, et al. Nosology and classification of genetic skeletal disorders: 2010 revision. American journal of medical genetics Part A 2011; 155A(5): 943-68.

30. Caliebe J, Broekman S, Boogaard M, et al. IGF1, IGF1R and SHOX Mutation Analysis in Short Children Born Small for Gestational Age and Short Children with Normal Birth Size (Idiopathic Short Stature). Horm Res Paediatr 2012; 77(4): 250-60.

31. Kant SG, Cervenkova I, Balek L, et al. A novel variant of FGFR3 causes proportionate short stature. European journal of endocrinology / European Federation of Endocrine Societies 2015; 172(6): 763-70.

32. Flechtner I, Lambot-Juhan K, Teissier R, et al. Unexpected high frequency of skeletal dysplasia in idiopathic short stature and small for gestational age patients. European journal of endocrinology / European Federation of Endocrine Societies 2014; 170(5): 677-84.

33. Wakeling EL, Brioude F, Lokulo-Sodipe O, et al. Diagnosis and management of Silver-Russell syndrome: first international consensus statement. Nature reviews Endocrinology 2017; 13(2): 105-24. 34. Begemann M, Zirn B, Santen G, et al. Paternally Inherited IGF2 Mutation and Growth Restriction. The New England journal of medicine 2015; 373(4): 349-56.

35. Cheon CK. Genetics of Prader-Willi syndrome and Prader-Will-Like syndrome. Annals of pediatric endocrinology \& metabolism 2016; 21(3): 126-35.

36. Thiele S, Mantovani G, Barlier A, et al. From pseudohypoparathyroidism to inactivating PTH/PTHrP signalling disorder (iPPSD), a novel classification proposed by the EuroPHP network. European journal of endocrinology / European Federation of Endocrine Societies 2016; 175(6): P1-P17.

37. Ioannides Y, Lokulo-Sodipe K, Mackay DJ, Davies JH, Temple IK. Temple syndrome: improving the recognition of an underdiagnosed chromosome 14 imprinting disorder: an analysis of 51 published cases. Journal of medical genetics 2014; 51(8): 495-501.

38. Silventoinen K. Determinants of variation in adult body height. Journal of biosocial science 2003; 35(2): 263-85.

39. Silventoinen K, Sammalisto S, Perola M, et al. Heritability of adult body height: a comparative study of twin cohorts in eight countries. Twin research : the official journal of the International Society for Twin Studies 2003; 6(5): 399-408.

40. Visscher PM. Sizing up human height variation. Nature genetics 2008; 40(5): 489-90.

41. Wood AR, Esko T, Yang J, et al. Defining the role of common variation in the genomic and biological architecture of adult human height. Nature genetics 2014; 46(11): 1173-86.

42. Marouli E, Graff M, Medina-Gomez C, et al. Rare and low-frequency coding variants alter human adult height. Nature 2017; 542(7640): 186-90.

43. Yang J, Bakshi A, Zhu Z, et al. Genetic variance estimation with imputed variants finds negligible missing heritability for human height and body mass index. Nature genetics 2015; 47(10): 1114-20.

44. Day FR, Thompson DJ, Helgason H, et al. Genomic analyses identify hundreds of variants associated with age at menarche and support a role for puberty timing in cancer risk. Nature genetics $2017 ; 49(6)$ : 834-41. 45. Rao E, Weiss B, Fukami M, et al. Pseudoautosomal deletions encompassing a novel homeobox gene cause growth failure in idiopathic short stature and Turner syndrome. Nature genetics 1997; 16(1): 54-63. 46. Hirschfeldova K, Solc R, Baxova A, et al. SHOX gene defects and selected dysmorphic signs in patients of idiopathic short stature and Leri-Weill dyschondrosteosis. Gene 2012; 491(2): 123-7.

47. Huber C, Rosilio M, Munnich A, Cormier-Daire V, French SGM. High incidence of SHOX anomalies in individuals with short stature. Journal of medical genetics 2006; 43(9): 735-9.

48. Jorge AA, Souza SC, Nishi MY, et al. SHOX mutations in idiopathic short stature and Leri-Weill dyschondrosteosis: frequency and phenotypic variability. Clinical endocrinology 2007; 66(1): 130-5. 

noncoding element deletions/duplications in Colombian patients with idiopathic short stature. Molecular genetics \& genomic medicine 2014; 2(2): 95-102.

515 50. Benito-Sanz S, Aza-Carmona M, Rodriguez-Estevez A, et al. Identification of the first PAR1 deletion encompassing upstream SHOX enhancers in a family with idiopathic short stature. European journal of human genetics : EJHG 2012; 20(1): 125-7.

518 51. Benito-Sanz S, Barroso E, Heine-Suner D, et al. Clinical and molecular evaluation of SHOX/PAR1

519 duplications in Leri-Weill dyschondrosteosis (LWD) and idiopathic short stature (ISS). The Journal of clinical endocrinology and metabolism 2011; 96(2): E404-12.

52. Benito-Sanz S, Thomas NS, Huber C, et al. A novel class of Pseudoautosomal region 1 deletions downstream of SHOX is associated with Leri-Weill dyschondrosteosis. American journal of human genetics 2005; 77(4): 533-44.

53. Chen J, Wildhardt G, Zhong Z, et al. Enhancer deletions of the SHOX gene as a frequent cause of short stature: the essential role of a $250 \mathrm{~kb}$ downstream regulatory domain. Journal of medical genetics 2009; 46(12): 834-9.

54. Donze SH, Meijer CR, Kant SG, et al. The growth response to GH treatment is greater in patients with SHOX enhancer deletions compared to SHOX defects. European journal of endocrinology / European Federation of Endocrine Societies 2015; 173(5): 611-21.

55. Olney RC, Bukulmez H, Bartels CF, et al. Heterozygous mutations in natriuretic peptide receptor-B (NPR2) are associated with short stature. The Journal of clinical endocrinology and metabolism 2006; 91(4): 1229-32.

56. Vasques GA, Amano N, Docko AJ, et al. Heterozygous mutations in natriuretic peptide receptor-B (NPR2) gene as a cause of short stature in patients initially classified as idiopathic short stature. The Journal of clinical endocrinology and metabolism 2013; 98(10): E1636-44.

57. Hisado-Oliva A, Garre-Vazquez AI, Santaolalla-Caballero F, et al. Heterozygous NPR2 Mutations Cause Disproportionate Short Stature, Similar to Leri-Weill Dyschondrosteosis. The Journal of clinical endocrinology and metabolism 2015; 100(8): E1133-42.

58. Inoue $\mathrm{H}$, Kangawa N, Kinouchi A, et al. Identification and functional analysis of novel human growth hormone secretagogue receptor (GHSR) gene mutations in Japanese subjects with short stature. The Journal of clinical endocrinology and metabolism 2011; 96(2): E373-8.

59. Batey L, Moon JE, Yu Y, et al. A novel deletion of IGF1 in a patient with idiopathic short stature provides insight Into IGF1 haploinsufficiency. The Journal of clinical endocrinology and metabolism 2014; 99(1): E153-9.

60. Yang Y, Huang H, Wang W, Yang L, Xie LL, Huang W. Association of insulin growth factor-1 receptor gene polymorphisms with genetic susceptibility to idiopathic short stature. Genetics and molecular research : GMR 2013; 12(4): 4768-79.

61. Domene HM, Scaglia PA, Martinez AS, et al. Heterozygous IGFALS gene variants in idiopathic short stature and normal children: impact on height and the IGF system. Hormone research in paediatrics 2013; 80(6): 413-23.

62. Dauber A, Munoz-Calvo MT, Barrios V, et al. Mutations in pregnancy-associated plasma protein A2 cause short stature due to low IGF-I availability. EMBO molecular medicine 2016; 8(4): 363-74.

63. de Graaff LC, Clark AJ, Tauber M, et al. Association analysis of ten candidate genes in a large multinational cohort of small for gestational age children and children with idiopathic short stature (NESTEGG study). Hormone research in paediatrics 2013; 80(6): 466-76.

64. Fusco I, Babu D, Mellone S, et al. Variations in the high-mobility group-A2 gene (HMGA2) are associated with idiopathic short stature. Pediatric research 2015.

65. Cai X, Ding H, Liu Y, et al. Expression of HMGB2 indicates worse survival of patients and is required for the maintenance of Warburg effect in pancreatic cancer. Acta biochimica et biophysica Sinica 2017; 49(2): 119-27.

66. Gao J, Zou Z, Gao J, et al. Increased expression of HMGB3: a novel independent prognostic marker of worse outcome in patients with esophageal squamous cell carcinoma. International journal of clinical and experimental pathology 2015; 8(1): 345-52.

67. Li M, Cai Y, Zhao H, et al. Overexpression of HMGB3 protein promotes cell proliferation, migration and is associated with poor prognosis in urinary bladder cancer patients. Tumour biology: the journal of the International Society for Oncodevelopmental Biology and Medicine 2015; 36(6): 4785-92.

68. Miotto B, Chibi M, Xie P, et al. The RBBP6/ZBTB38/MCM10 axis regulates DNA replication and common fragile site stability. Cell reports 2014; 7(2): 575-87.

69. Marques D, Ferreira-Costa LR, Ferreira-Costa LL, et al. Association of insertion-deletions polymorphisms with colorectal cancer risk and clinical features. World journal of gastroenterology 2017; 23(37): 6854-67. 
70. Wang SR, Carmichael H, Andrew SF, et al. Large-scale pooled next-generation sequencing of 1077 genes to identify genetic causes of short stature. The Journal of clinical endocrinology and metabolism 2013; 98(8): E1428-37.

71. Mikhail FM. Copy number variations and human genetic disease. Current opinion in pediatrics 2014; 26(6): 646-52.

72. Dauber A, Yu Y, Turchin MC, et al. Genome-wide association of copy-number variation reveals an association between short stature and the presence of low-frequency genomic deletions. American journal of human genetics 2011; 89(6): 751-9.

73. Canton AP, Costa SS, Rodrigues TC, et al. Genome-wide screening of copy number variants in children born small for gestational age reveals several candidate genes involved in growth pathways. European journal of endocrinology / European Federation of Endocrine Societies 2014; 171(2): 253-62.

74. Wit JM, van Duyvenvoorde HA, van Klinken JB, et al. Copy number variants in short children born small for gestational age. Hormone research in paediatrics 2014; 82(5): 310-8.

75. Zahnleiter D, Uebe S, Ekici AB, et al. Rare copy number variants are a common cause of short stature. PLoS genetics 2013; 9(3): e1003365.

76. van Duyvenvoorde HA, Lui JC, Kant SG, et al. Copy number variants in patients with short stature. European journal of human genetics : EJHG 2014; 22(5): 602-9.

77. Nilsson O, Guo MH, Dunbar N, et al. Short stature, accelerated bone maturation, and early growth cessation due to heterozygous aggrecan mutations. The Journal of clinical endocrinology and metabolism 2014; 99(8): E1510-8.

78. Tompson SW, Merriman B, Funari VA, et al. A recessive skeletal dysplasia, SEMD aggrecan type, results from a missense mutation affecting the C-type lectin domain of aggrecan. American journal of human genetics 2009; 84(1): 72-9.

79. Guo MH, Shen Y, Walvoord EC, et al. Whole exome sequencing to identify genetic causes of short stature. Horm Res Paediatr 2014; 82(1): 44-52.

80. Malaquias AC, Scalco RC, Fontenele EG, et al. The sitting height/height ratio for age in healthy and short individuals and its potential role in selecting short children for SHOX analysis. Hormone research in paediatrics 2013; 80(6): 449-56.

81. Zhang YQ, Li H. Reference charts of sitting height, leg length and body proportions for Chinese children aged 0-18 years. Annals of human biology 2015; 42(3): 223-30.

82. Fredriks AM, van Buuren S, van Heel WJ, Dijkman-Neerincx RH, Verloove-Vanhorick SP, Wit JM. Nationwide age references for sitting height, leg length, and sitting height/height ratio, and their diagnostic value for disproportionate growth disorders. Archives of disease in childhood 2005; 90(8): 807-12.

83. Miller DT, Adam MP, Aradhya S, et al. Consensus statement: chromosomal microarray is a first-tier clinical diagnostic test for individuals with developmental disabilities or congenital anomalies. American journal of human genetics 2010; 86(5): 749-64.

84. Dauber A, Rosenfeld RG, Hirschhorn JN. Genetic evaluation of short stature. J Clin Endocrinol Metab 2014; 99(9): 3080-92.

85. Domene HM, Hwa V, Argente J, et al. Human acid-labile subunit deficiency: clinical, endocrine and metabolic consequences. Hormone research 2009; 72(3): 129-41.

86. Scaglia PA, Keselman AC, Braslavsky D, et al. Characterization of four Latin American families confirms previous findings and reveals novel features of acid-labile subunit deficiency. Clinical endocrinology 2017; 87(3): 300-11.

87. Domene HM, Hwa V, Jasper HG, Rosenfeld RG. Acid-labile subunit (ALS) deficiency. Best practice \& research Clinical endocrinology \& metabolism 2011; 25(1): 101-13.

88. Klammt J, Kiess W, Pfaffle R. IGF1R mutations as cause of SGA. Best practice \& research Clinical endocrinology \& metabolism 2011; 25(1): 191-206.

89. Walenkamp MJ, de Muinck Keizer-Schrama SM, de Mos M, et al. Successful long-term growth hormone therapy in a girl with haploinsufficiency of the insulin-like growth factor-I receptor due to a terminal 15q26.2->qter deletion detected by multiplex ligation probe amplification. The Journal of clinical endocrinology and metabolism 2008; 93(6): 2421-5.

90. Gkourogianni A, Andrew M, Tyzinski L, et al. Clinical characterization of patients with autosomal dominant short stature due to aggrecan mutations. J Clin Endocrinol Metab 2016: jc20163313.

91. Dos Santos C, Essioux L, Teinturier C, Tauber M, Goffin V, Bougneres P. A common polymorphism of the growth hormone receptor is associated with increased responsiveness to growth hormone. Nature genetics 2004; 36(7): 720-4.

92. Renehan AG, Solomon M, Zwahlen M, et al. Growth hormone receptor polymorphism and growth hormone therapy response in children: a Bayesian meta-analysis. American journal of epidemiology 2012; 175(9): 867-77. 
93. Cohen P, Germak J, Rogol AD, et al. Variable degree of growth hormone (GH) and insulin-like growth factor (IGF) sensitivity in children with idiopathic short stature compared with GH-deficient patients: evidence from an IGF-based dosing study of short children. The Journal of clinical endocrinology and metabolism 2010; 95(5): 2089-98.

94. Wit JM, de Luca F. Atypical defects resulting in growth hormone insensitivity. Growth Horm IGF Res 2016; 28: 57-61.

95. Hanson D, Murray PG, Coulson T, et al. Mutations in CUL7, OBSL1 and CCDC8 in 3-M syndrome lead to disordered growth factor signalling. Journal of molecular endocrinology 2012; 49(3): 267-75. 96. Munoz-Calvo MT, Barrios V, Pozo J, et al. Treatment With Recombinant Human Insulin-Like Growth Factor-1 Improves Growth in Patients With PAPP-A2 Deficiency. The Journal of clinical endocrinology and metabolism 2016; 101(11): 3879-83. 97. Lupu F, Terwilliger JD, Lee K, Segre GV, Efstratiadis A. Roles of growth hormone and insulin-like growth factor 1 in mouse postnatal growth. Dev Biol 2001; 229(1): 141-62. Endocrinology 2015; 11(12): 735-46.

646 99. Wit JM, Oostdijk W, Losekoot M, van Duyvenvoorde HA, Ruivenkamp CA, Kant SG.

647 MECHANISMS IN ENDOCRINOLOGY: Novel genetic causes of short stature. European journal of endocrinology / European Federation of Endocrine Societies 2016; 174(4): R145-73. 


\begin{tabular}{|c|c|c|}
\hline Mechanistic Class & Representative Monogenic Causes & Typical Phenotype \\
\hline Insulin/IGF Pathways & $\begin{array}{l}\text { Insulin-like Growth Factor } 1 \text { Receptor (IGF1R) Insulin-like } \\
\text { Growth Factor } 1 \text { (IGF1), Insulin-like Growth Factor } 2 \text { (IGF2), } \\
\text { Insulin Receptor (INSR), }\end{array}$ & $\begin{array}{l}\text { SGA and postnatal growth retardation. } \\
\text { Dysglycemia Common. }\end{array}$ \\
\hline $\begin{array}{l}\text { Growth plate and } \\
\text { Skeletal Dysplasia }\end{array}$ & $\begin{array}{l}\text { Short Stature Homeobox (SHOX), Naturetic Peptide Receptor } 2 \\
\text { (NPR2), Aggrecan (ACAN), Fibroblast Growth Factor Receptor } 3 \\
\text { (FGFR3) }\end{array}$ & $\begin{array}{l}\text { Variable features of skeletal dysplasia, some } \\
\text { present as typical ISS }\end{array}$ \\
\hline $\begin{array}{l}\text { DNA replication/repair, } \\
\text { chromosome structure } \\
\text { and transcription }\end{array}$ & $\begin{array}{l}\text { Chromatin Helicase DNA binding Protein } 7 \text { (CHD7), Fanconi } \\
\text { Anaemia Complementation Groups (FANCA, FANCC, FANCG), } \\
\text { Cell Division Cycle 6 (CDC6), Centromeric Protein J (CENPJ) }\end{array}$ & $\begin{array}{l}\text { Increased risk of malignancy, SGA with } \\
\text { microcephaly }\end{array}$ \\
\hline $\begin{array}{l}\text { Signal transduction, } \\
\text { Rasopathies }\end{array}$ & $\begin{array}{l}\text { Protein-Tyrosine Phosphatase Nonreceptor-type } 11 \text { (PTPN11), } \\
\text { V-Raf-1 Murine Leukemia Viral Oncogene Homolog } 1 \text { (RAF1), } \\
\text { Kirsten Rat Sarcoma Viral Oncogene Homolog (KRAS), } \\
\text { Phosphatidylinositol 3-kinase Regulatory Subunit } 1 \text { (PIK3R1), } \\
\end{array}$ & $\begin{array}{l}\text { Normal size at birth, normal head size, } \\
\text { postnatal growth impairment, dysmorphism. }\end{array}$ \\
\hline $\begin{array}{l}\text { Ubiquitination and } \\
\text { Protein Folding }\end{array}$ & $\begin{array}{l}\text { Cullin } 7 \text { (CUL7), Obscurin-like } 1 \text { (OBSL1), Coiled Coil Domain } \\
\text { Containing } 8 \text { (CCDC8), Tripartite Motif-Containing Protein } 37 \\
\text { (TRIM37), Ubiquitin Protein Ligase E3 Component N-Recognin } \\
1 \text { (UBR1), }\end{array}$ & $\begin{array}{l}\text { SGA with normocephaly and normal } \\
\text { intelligence. }\end{array}$ \\
\hline
\end{tabular}

653

Legend Conditions have been divided by the mechanism underlying the growth impairment and a broad phenotypic description given for each mechanistic group. A more extensive listing of monogenic short stature disorders can be found in the review by Wit et $\mathrm{al}^{99}$ 
659 Figure 1. Typical growth Curves for: A) average male, B) Constitutional Delay of Growth and Puberty, and

660 C) Idiopathic Short Stature (ISS). Arrow indicate age of peak pubertal growth velocity.

661 Figure 2. Proposed schema for molecular diagnosis in the child with Short Stature of Undetermined

662 Aetiology. The latter is defined as short stature <-2 SDS, \pm being born small for gestational age, with no readily 663 recognisable syndrome diagnosis, no significant microcephaly, and screening investigations normal (e.g.

664 karyotype [in females], routine bloods to exclude occult system disease, thyroid function) and not GH deficient

665 by standard GH stimulation testing. Each box contains a potential clinical scenario leading to an investigation

666 strategy.

667 Clinical Scenario 1: The short child or the short adolescent with delayed puberty with no clinical features of 668 system disease, endocrinopathy or skeletal disorder, and in some a family history of a similar growth pattern.

669 Clinical Scenario 2: The short child/adolescent with features that could indicate the presence of a skeletal 670 disorder (minor disproportion, any bone length/size abnormality, advanced bone age).

671 Clinical Scenario 3: A child with more significant short stature (Height SDS <-3) with minor dysmorphic 672 features suggestive but not in itself diagnostic of a known syndrome.

673 Clinical Scenario 4: GH-IGF testing could indicate a defect in the axis e.g. high GH levels and low IGF-I [GH 674 receptor mutation] / normal GH and high IGF-I [IGF-I receptor mutation] / very high IGF-I and IGFBP-3 levels 675 [PAPP-A2 mutation] / undetectable acid labile subunit levels [ALS mutation].

676 Clinical Scenario 5: A child with more significant short stature (Height SDS <-3) with minor dysmorphic 677 features not suggesting a diagnosis \pm a family history.

Figure 3. Advancement in genetic approach to short stature by decade. Turner syndrome was first noted to be due monosomy $\mathrm{X}$ and later expanded to include other abnormalities of sex chromosome complement (mosaicism, partial deletions). Four decades later, SHOX deficiency was found to be the cause of Leri-Weill syndrome and also in patients with non-syndromic short stature. SHOX deficiency also contributes to the short stature in Turner syndrome. Silver Russell syndrome (a condition with both prenatal and postnatal growth retardation) is due to epigenetic changes in methylation that restrain IGF-2 expression. Genome wide scans for copy number variations (CNV) and application of Next Generation Sequencing (NGS) are being currently 


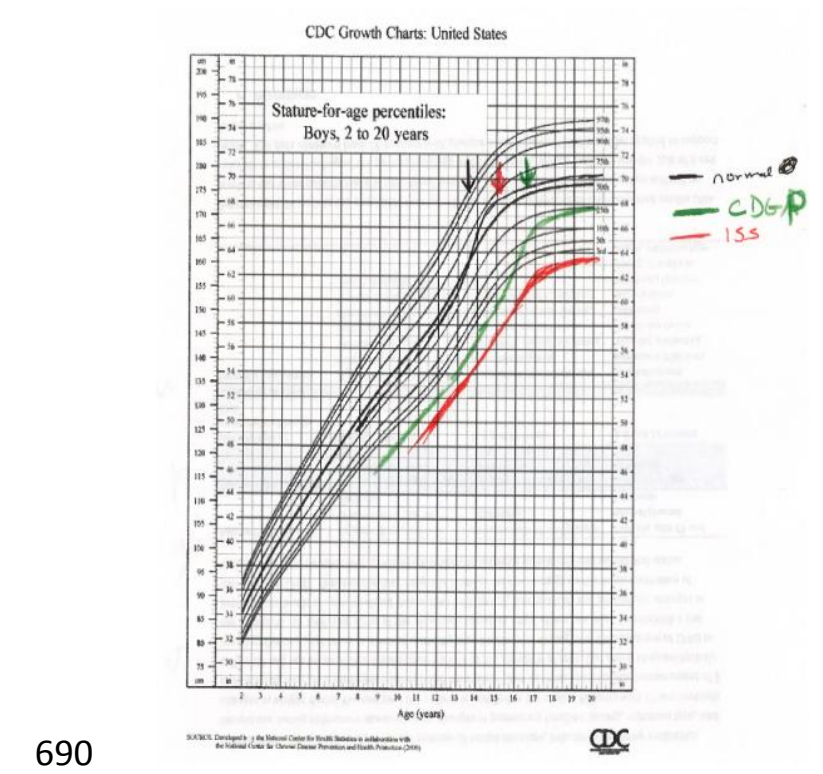

691

692 Figure 2

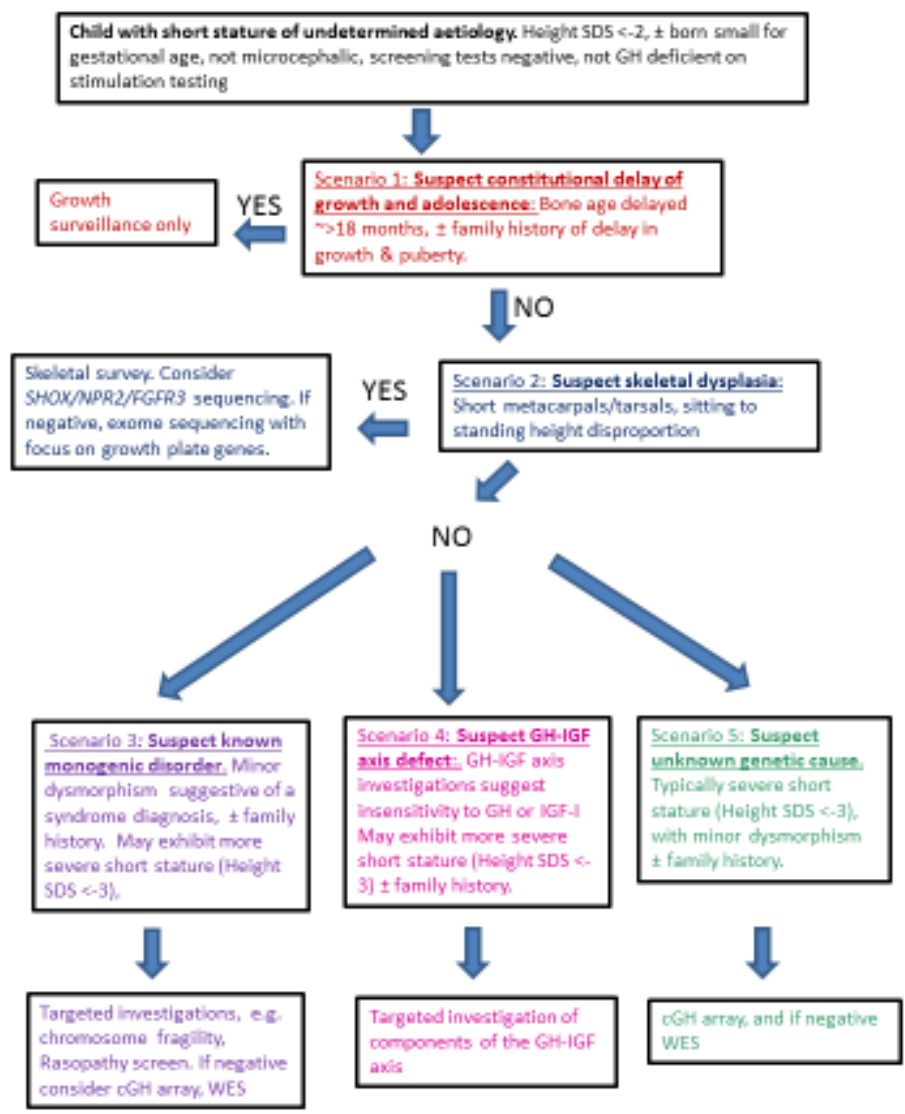


699 Figure 3

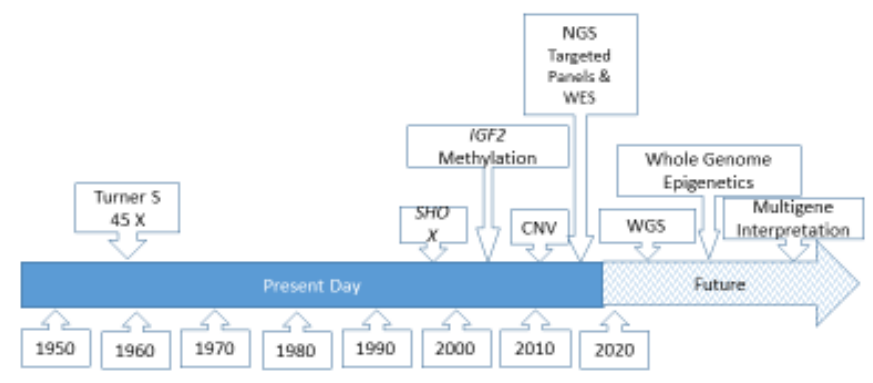

700 